\title{
Modelling effects of tidal currents on waves at a tidal stream energy site.
}

\author{
Nicolas Guillou ${ }^{\mathrm{a}, *}$ \\ ${ }^{a}$ Laboratoire de Génie Côtier et Environnement (LGCE), Cerema/DTecEMF/ER, 155 rue Pierre Bouguer, Technopôle \\ Brest-Iroise - BP 5 - 29280 Plouzané, France
}

\begin{abstract}
Whereas tidal stream energy sites may be characterised by significant wave and current interactions, numerical resource assessments routinely ignored these processes neglecting, in particular, current-induced modifications of waves. Here, these effects are investigated in locations exposed to ocean waves, evaluating performances of a phase-averaged numerical wave model to approach observed semi-diurnal modulations of wave heights, periods and directions, off and within the Fromveur Strait (western Brittany), a region with strong potential for tidal array development. The introduction of tidal forcings in the wave model is found to improve predictions by approaching the large-scale influence of current-induced refraction leading to variations of the significant wave height by nearly $30 \%$ at the deep-water wave buoy. The model reproduces furthermore, with the inclusion of an additional dissipation term, the localised steepening and waves breaking on negative current gradients, limiting the overestimation of the significant wave height at the shallow-water wave buoy within the Fromveur Strait. Tidal currents may finally lead to a strong increase in wave power, over $100 \%$ in northern entrances of straits, contributing to the variability of the wave energy flux.

Keywords: marine renewable energy, SWAN, wave-current interactions, unstructured grid, Brittany, western Europe.
\end{abstract}

\section{Introduction}

Numerical modelling tools are most of the time retained, at the early stages of a tidal farm project, to complement in-situ observations in quantifying and characterising available kinetic energy and provide potential developers with key information for ensuring successful design and deployment of energy converters in the marine environment [e.g., 1, 2, 3, 4]. Nevertheless, whereas stream energy sites may be characterised by significant wave and current interactions leading to (1) increased fatigue and loading upon tidal turbines $[5,6],(2)$ reduction of tidal stream power by $10-20 \%$ for extreme winter waves $[7,8]$ and $(3)$ variations of

\footnotetext{
* Corresponding author

Email address: nicolas.guillou@cerema.fr (Nicolas Guillou )
} 
wave energy flux up to $60 \%$ [9], little effort has been devoted to improve predictions of these interactions at locations identified for array implementation.

As tidal stream sites encounter typically strong currents, over $2.5 \mathrm{~m} \mathrm{~s}^{-1}$ [e.g., 9, 10, 11], with significant spatial gradients in amplitude and direction, further investigations are more specifically required in modelling effects of small-scale currents on waves in these specific high-energy locations. Nevertheless, previous numerical assessments of these effects have mainly been addressed in semi-enclosed configurations like estuaries or tidal inlets $[12,13,14,15]$, neglecting configurations opened to ocean waves like tidal straits which account for a significant part of first generation tidal stream sites [16]. Apart from a few studies [17, 18, 19, 20], currents effects on waves are also routinely ignored in regional assessments of the wave energy resource. The major recent numerical investigations of currents effects on waves at opened tidal stream sites have been conducted by Ardhuin et al. [21] in the Fromveur Strait (western Brittany, France, Fig. 1) and Saruwatari et al. [9] in the Pentland Firth and the Orkney archipelago (Scotland, United Kingdom). Nevertheless, whereas Saruwatari et al. [9] exhibited significant increases in wave heights between 150 and $200 \%$ in conditions of opposed waves and tidal currents, the comparison between numerical results and in-situ observations did not establish improvements of waves simulation with currents, mainly as reduced tidal modulations of waves

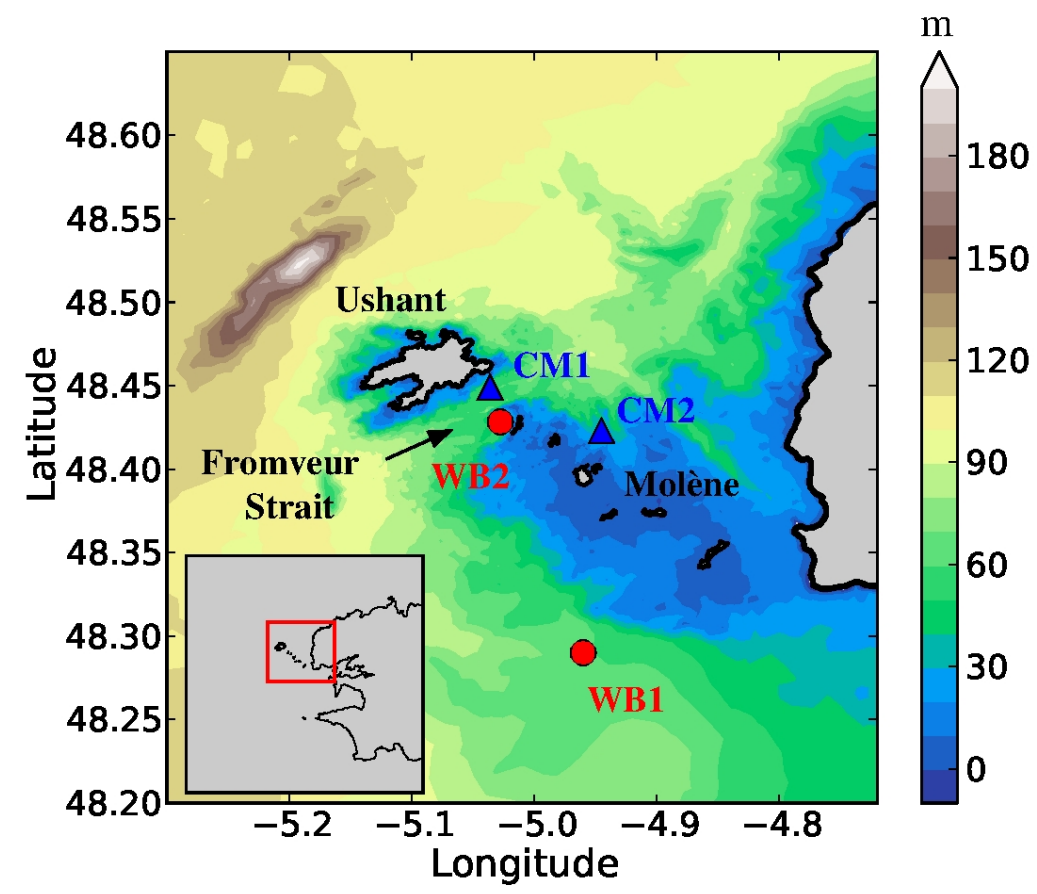

Figure 1: Bathymetry of the Fromveur Strait with locations of available measurements sites for wave buoys, $\boldsymbol{\Delta}$ for current meters, Table 1). Water depth is relative to mean sea level. The left-bottom snapshot shows the location of the area of interest off western Brittany. 
Table 1: Description of measurement sites.

\begin{tabular}{|c|c|c|c|}
\hline \multirow{2}{*}{$\begin{array}{l}\text { Station } \\
\text { number }\end{array}$} & \multicolumn{2}{|c|}{ Coordinates } & \multirow{2}{*}{$\begin{array}{c}\text { Water depths } \\
\qquad(\mathrm{m})\end{array}$} \\
\hline & Lon. & Lat. & \\
\hline CM1 & $5.036^{\circ} \mathrm{W}$ & $48.449^{\circ} \mathrm{N}$ & 53 \\
\hline CM2 & $4.945^{\circ} \mathrm{W}$ & $48.423^{\circ} \mathrm{N}$ & 29 \\
\hline WB1 & $4.960^{\circ} \mathrm{W}$ & $48.290^{\circ} \mathrm{N}$ & 60 \\
\hline WB2 & $5.027^{\circ} \mathrm{W}$ & $48.428^{\circ} \mathrm{N}$ & 25 \\
\hline
\end{tabular}

parameters (including wave height, period and direction) were obtained at measurements sites. Benefits of integrating tidal currents in wave-height simulations have however been exhibited by Ardhuin et al. [21] as part of a general discussion about performances of numerical models in conditions with strong currents. Nevertheless, the evaluation of predictions was restricted to measurements at more than $15 \mathrm{~km}$ from the tidal stream site (point WB1, Fig. 1) setting aside improvements of simulations in the area considered for tidal array development.

The present study extends these numerical investigations relying on a modified version of a phaseaveraged spectral wave model (1) coupled with a tidal circulation model and (2) assessed against in-situ measurements of current-impacted waves parameters (wave height, period and direction) in the tidal stream site of the Fromveur Strait. Whereas a simplified analytical method, based on linear wave theory, has been recently proposed by Hashemi et al. [22] to estimate, with reduced computational costs, the effects of tidal currents on the wave power resource, this approach is not retained here as it only applies for colinearity situation between waves and currents neglecting further processes such as waves breaking and blocking by opposing currents [23, 24]. As such situations are liable to occur in tidal stream sites [21], the present investigation is based on numerical wave modelling liable to encompass the processes of generation, dissipation and nonlinear wave-wave interactions from offshore opened ocean to coastal regions [25]. Besides the well-known modulations of currents on waves including especially current-induced refraction [26], particular effort is devoted here to improve numerical estimates of breaking dissipation of waves on negative current gradients [27]. These investigations may thus contribute to refined estimations of wave power [20], available tidal kinetic energy $[7,8]$ and wave loading on submerged tidal turbines [9] in stream sites with moderate to strong wave conditions. The present study presents, in particular, a strong connection with the investigation performed by Guillou et al. [8] on waves effects on the tidal stream power of the Fromveur Strait.

After a description of the study region (Section 2.1), the emphasis is put on the theoretical formulations and the implementation of the numerical model (Sections 2.2 and 2.3). Predictions are evaluated against in-situ observations of waves parameters (significant wave height, peak period and mean wave direction) and current amplitude and direction (Section 3.1) exhibiting local improvements reached by integrating 
effects of tidal currents in wave modelling (Section 3.2). Processes of currents effects on waves in the location considered are finally investigated focusing on current-induced refraction (Section 3.3.1) and waves breaking on negative current gradients (Section 3.3.2). In the perspective of the implementation of wave energy converters complemented tidal stream energy devices, a detailed analysis of these predictions is finally conducted to exhibit the effects of tidal currents on the wave power resource (Section 3.4).

\section{Materials and methods}

\subsection{Site of application}

The site of application is the Fromveur Strait, off western Brittany, which separates the isle of Ushant from the Molène archipelago, composed of a group of islets and rocks, through a $2 \mathrm{~km}$ wide and $50 \mathrm{~m}$ deep strait (Fig. 1). This location shows, after the Alderney Race in the English Channel, the second largest tidal currents along the coast of France with maximum surface velocities of up to $3.8 \mathrm{~m} \mathrm{~s}^{-1}$ [28, 29]. During mean spring tide, maximum tidal stream power may also reach values over $20 \mathrm{~kW} \mathrm{~m}^{-2}$ at $10 \mathrm{~m}$ above the seabed, the assumed technology hub height for this region $[8,11]$. The Fromveur Strait is thus considered as one of the leading French tidal stream sites with a selection, by the French government, of a restricted area of $4 \mathrm{~km}^{2}$ within the strait for the implementation of tidal stream arrays [11]. Despite the shelter provided by the isle of Ushant, the Strait experiences furthermore strong incoming waves with averaged and maximum significant wave heights estimated at 1.5 and $5.0 \mathrm{~m}$, respectively [20,30]. This location is thus characterised by strong interactions between tidal currents and waves as exhibited by the observed semi-diurnal modulations of the significant wave height, with a period of $12.5 \mathrm{~h}$ related to the dominant M2 tide, off (WB1) and within (WB2) the Fromveur Strait (Fig. 2). These modulations are particularly noticeable during spring tidal conditions. Resuming the rough estimation of Hashemi et al. [22] based on the formulation proposed by Moreira and Peregrine [31], blocking of waves with a period of $9 \mathrm{~s}$, typical of the area of interest, may appear for tidal currents of $3.5 \mathrm{~m} \mathrm{~s}^{-1}$. The Fromveur Strait can thus be the place of processes of waves breaking and blocking by opposing currents. Further details about the study region are available in [8] and [11].

\subsection{Model theoretical formulation}

The modelling approach is based on the phase-averaged spectral wave model SWAN (Simulating WAves Nearshore) (version 41.01) [32, 33]. SWAN computes the evolution of the action density $N=E / \sigma$, with $E$ the wave energy density distributed over intrinsic frequencies $\sigma$ and propagation directions $\theta$, by solving the time-dependent spectral action balance equation [34]. This equation expresses the conservation of the action density between (1) propagation terms in geographical and spectral spaces and (2) source and sink terms which generate, dissipate or redistribute wave energy. The parameterisation adopted here for each terms is 

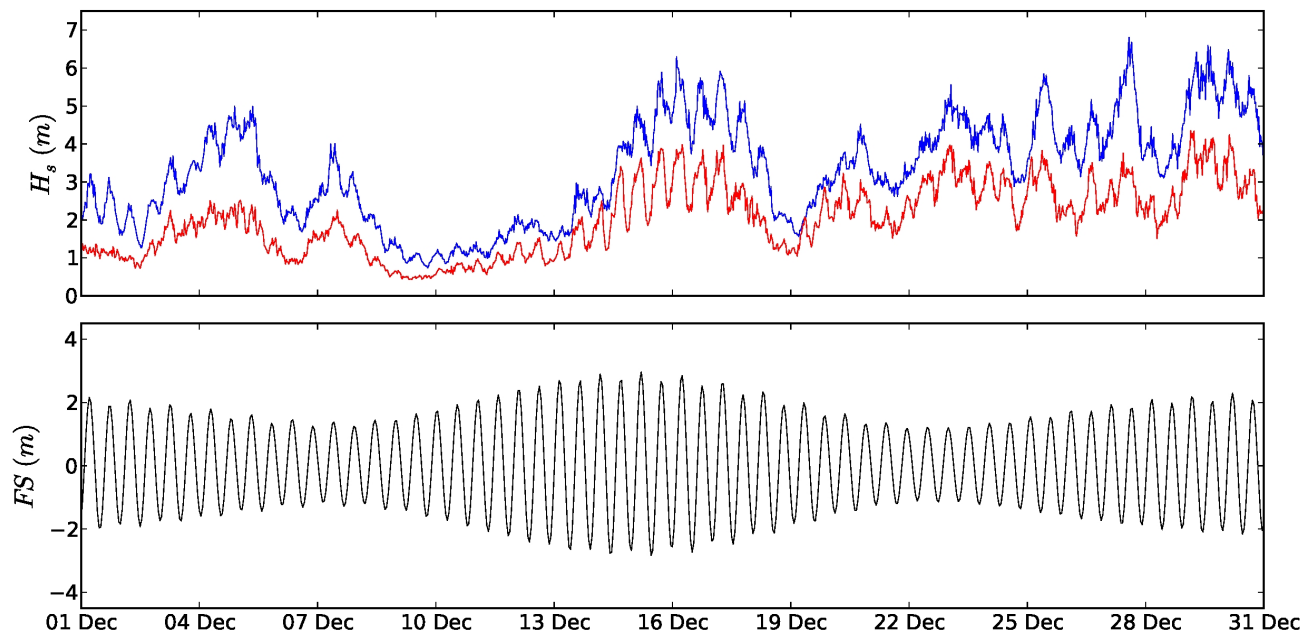

Figure 2: Measured time series of the significant wave height $H_{s}$ at wave buoys WB1 (blue line) and WB2 (red line) (Fig. 1 and Table 1) and predicted tidal free-surface elevation FS in the Fromveur Strait in December 2012.

taken from the implementation of SWAN (version 40.91) off western Brittany, by Guillou and Chapalain [20], for a medium-term evaluation of the wave energy resource. The model has been modified to integrate an additional dissipation term $S_{w c, c u r}$, recently proposed by van der Westhuysen [27] to limit the overprediction of wave height on negative current gradients (accelerating opposing currents or decelerating following currents) in combination with its saturation-based whitecapping formulation [35]. Such improvement of predictions is addressed with a formulation for the enhanced breaking dissipation of waves associated to the degree of current-induced steepening. The mathematical expression of this saturation-based parameterisation is briefly described hereafter:

$$
S_{w c, c u r}=-C_{d s}^{\prime} \max \left[\frac{c_{\sigma}(\sigma, \theta)}{\sigma}, 0\right]\left[\frac{B(k)}{B_{r}}\right]^{\frac{p}{2}} E(\sigma, \theta)
$$

where $c_{\sigma}$ is the propagation speed of the relative radian frequency. The density function $B(k)$ is the azimuthal-integrated spectral saturation calculated from frequency space variables as follows

$$
B(k)=\int_{0}^{2 \Pi} c_{g} k^{3} E(\sigma, \theta) d \theta
$$

where $k$ is the wave number and $c_{g}$ is the intrinsic group velocity. $B_{r}$ is the threshold saturation given by van der Westhuysen [35] as equal to $1.75 \times 10^{-3}$. The parameter $p$ is expressed as a function of the inverse wave age $u_{*} / c$ as follows

$$
p=3+\tanh \left[25.76\left(\frac{u_{*}}{c}-0.1\right)\right]
$$

where $u_{*}$ is the wind friction velocity and $c$ is the wave phase velocity. When compared with the original saturation-based expression of van der Westhuysen [35] for whitecapping energy dissipation by wave breaking, the additional term for energy dissipation by currents, $S_{w c, c u r}$, (1) neglects the shallow water scaling factor 
$\tanh (k d)^{(2-p) / 4}$ (with $d$ the total water depth) and (2) is enhanced by a factor $c_{\sigma} / \sigma$ which intends to isolate the normalised rate of increase in wave steepness due to the current alone. This term is only activated in situations of negative current gradients which may correspond to accelerating opposing or decelerating following currents. This enhanced dissipation term is not required in situations of positive current gradients. In the present investigation, this term will mainly impact waves directional components along the southwest/north-east orientation of the Fromveur Strait characterised by strong tidal currents gradients countering incoming waves. The calibration parameter $C_{d s}^{\prime}$ is finally set to a value of 0.65 obtained from the comparison of numerical predictions with observations from laboratory flume experiments of Lai et al. [36] and Suastika et al. [37].

According to most wave power assessments based on SWAN [20,30, 38, 39], the wave energy flux is computed as $P=\left(P_{x}^{2}+P_{y}^{2}\right)^{1 / 2}$ relying on default quantity outputs of energy transport components along $(x)$ and $(y)$ directions, $P_{x}$ and $P_{y}$.

\subsection{Model setup}

SWAN is implemented on the unstructured computational grid used by Guillou and Thiébot [11] for the evaluation of the environmental impact of tidal stream devices in the Fromveur Strait with the depthaveraged circulation model TELEMAC 2D [40]. This mesh comprises 19,068 nodes and 37,019 triangular finite elements with a size ranging from $10 \mathrm{~km}$ at offshore boundaries of western Brittany to less than $50 \mathrm{~m}$ in the Fromveur Strait. According to Guillou and Chapalain [20], the wave model runs here with a discretisation of 31 exponentially spaced frequencies ranging from 0.05 to $1 \mathrm{~Hz}, 30$ evenly spaced directions and a time step of $15 \mathrm{~min}$. Wave energy dissipation by bottom friction is furthermore parametrised integrating the heterogeneous distribution of seabed roughness length, based on sediment bottom types, which was found to improve nearshore waves predictions during storm events [41, 42]. To be consistent with predictions from the depth-averaged model TELEMAC 2D, this heterogeneous bottom friction is determined on the basis of the spatial distribution and parameterisation adopted by Guillou and Thiébot [11] for optimal predictions of tidal currents in the Fromveur Strait. Wind velocity components at $10 \mathrm{~m}$ above the free surface are provided, at hourly intervals and $0.2^{\circ}$ spatial resolution, by the Climate Forecast System Reanalysis (CFSR version 2) [43]. The wave model integrates furthermore the variations of tidal free-surface elevation and depth-averaged currents predicted, at 15 min intervals, by the version of TELEMAC 2D setup by Guillou and Thiébot [11] in western Brittany. SWAN is finally driven, along open boundaries of computational domain, by JONSWAP wave spectra established, at three hour intervals with a spatial resolution of $18 \mathrm{~km}$, on the basis of integrated wave parameters (significant wave height, peak period, direction and spreading) predicted by a regional run of WaveWatch III (WWIII) in the context of the IOWAGA project (Integrated Ocean WAves for Geophysical and other Applications, Ifremer, France) [44].

Simulations are conducted over the period November 2012-March 2013 which corresponds to the avail- 
ability of waves measurements in the area of interest. Effects of tides on waves are evaluated with three numerical experiments entitled E1, E2 and E3 (Table 2). Model predictions are assessed and compared with the standard statistical parameters of the mean absolute and relative differences $D I F F_{a b s}=\frac{1}{n} \sum_{i=1}^{i=n}\left|y_{i}-x_{i}\right|$ and $D I F F_{\text {rel }}=\frac{1}{n} \sum_{i=1}^{i=n}\left(y_{i}-x_{i}\right)$, the index of agreement $R E$ [45], and the Pearson's correlation coefficient $R$ where $n$ is the number of data in the discretised series considered, $\left(x_{i}\right)$ and $\left(y_{i}\right)$ represent the two sets of observed and/or simulated data.

Table 2: Numerical experiments retained.

\begin{tabular}{ccc}
\hline Numerical & Time-varying & Enhanced breaking \\
experiments & tidal effects & dissipation of waves $[27]$ \\
\hline E1 & & \\
E2 & $\checkmark$ & \\
E3 & $\checkmark$ & $\checkmark$ \\
\hline
\end{tabular}

\section{Results and discussion}

\subsection{Model validation}

Whereas the emphasis is put on the evaluation of wave model predictions, a brief description of the circulation model assessment is provided here. Predictions from TELEMAC 2D have thus been evaluated, by Guillou and Thiébot [11], against in-situ measurements of current amplitude and direction at sites CM1 and CM2 over the period March-June 1993 (Fig. 1). An overall good agreement is obtained for the approach of current amplitude at point CM1, $10 \mathrm{~m}$ above the bed, with an index $\mathrm{RE}=0.98$. Whereas the index of agreement for prediction of current amplitude decreases to a value of 0.78 at point CM2, simulations reproduce the pronounced observed asymmetry at this measurement point, characterised by strong and short north-eastern components and reduced long-lasted south-western velocities. Predictions appear also consistent with observations of current direction, approaching at the two sites the abrupt changes between south-west and north-east directed velocities. The synoptic comparison of predictions with the atlas of tidal currents provided by the French navy SHOM [46] confirms finally model's performances in spring conditions at the scale of Ushant-Molène archipelago. Further details about the assessment of simulations from the tidal circulation model are available in Guillou and Thiébot [11]. Predictions from TELEMAC 2D are thus considered sufficiently accurate for modelling effects of tidal currents on waves in SWAN.

The evaluation of wave model predictions is performed in configuration E3, over the period November 2012-March 2013, against in-situ measurements of significant wave height $H_{s}$, peak period $T_{p}$, and mean 

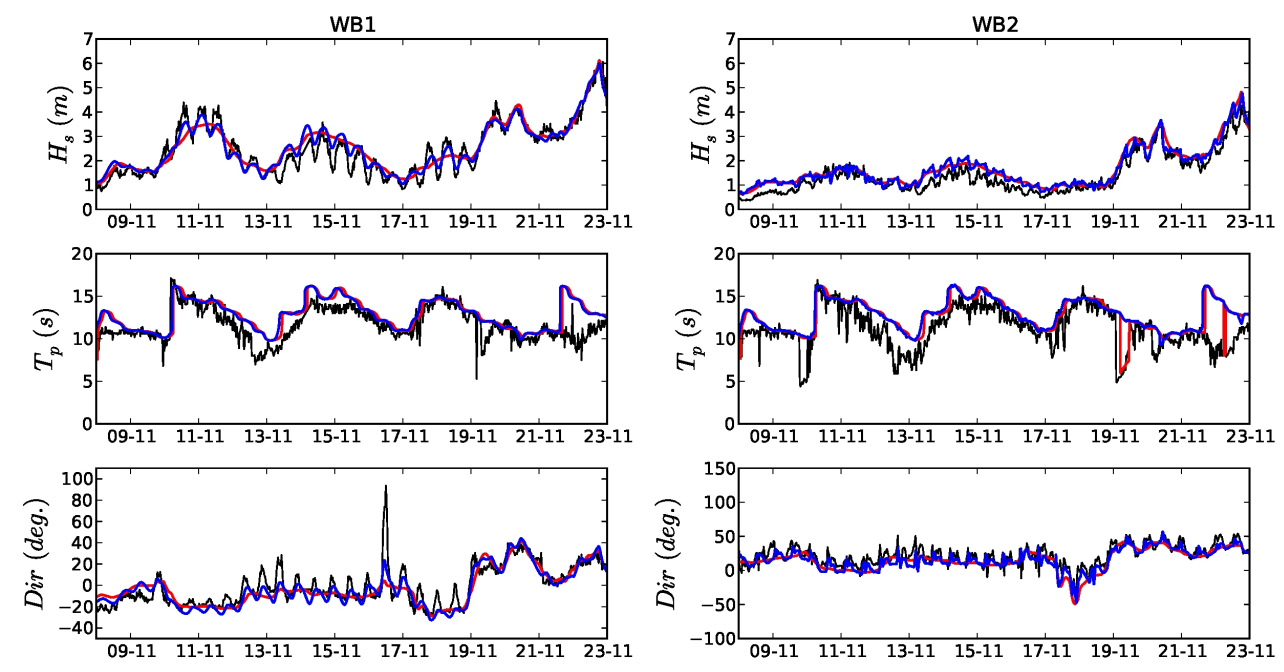

Figure 3: Measured (black line) and computed from configurations E1 (red line) and E3 (blue line) times series of significant wave height, peak period and mean wave direction (anticlockwise convention from the East) at wave buoys WB1 and WB2 in November 2012 .
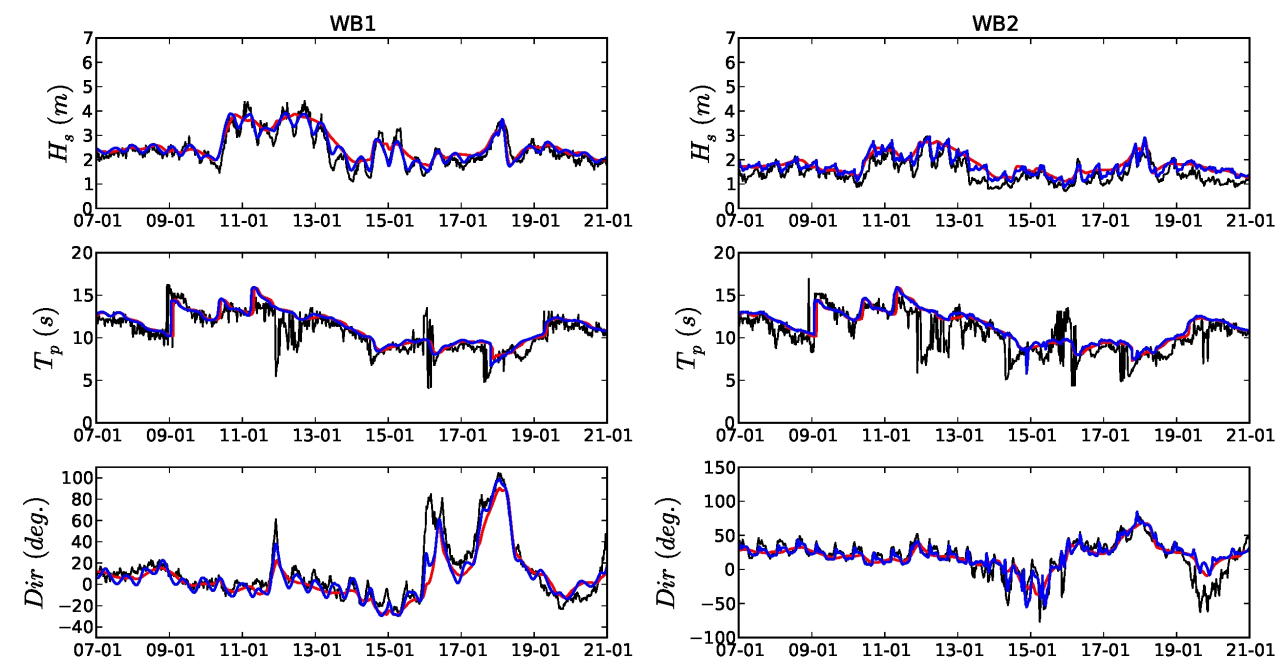

Figure 4: Measured (black line) and computed from configurations E1 (red line) and E3 (blue line) times series of significant wave height, peak period and mean wave direction (anticlockwise convention from the East) at wave buoys WB1 and WB2 in January 2013.

wave directions at wave buoys WB1 and WB2 (Figs. 3 and 4). Besides the global approach of the temporal evolutions of waves conditions, predictions in configuration E3 reproduce, at both measurement points, the observed semi-diurnal tidal modulation of the significant height, particularly noticeable during spring tide. Statistical evaluations of $H_{s}$ exhibit thus performances of the wave model with indexes of agreement $R E$ of 0.97 and 0.94 at points $\mathrm{WB} 1$ and WB2, respectively (Fig. 5). These performances are naturally emphasised for higher tidal ranges (over $3 \mathrm{~m}$ ), in spring conditions, with correlation coefficients of 0.96 at 
both measurements points (Fig. 6). Whereas increased differences between predictions and observations are obtained in estimations of periods and directions, numerical results show no particular bias in wave predictions with values of $R E$ remaining over 0.77 (Fig. 5). Predictions in configuration E3 approach thus the observed semi-diurnal variations of wave directions at both measurement points.
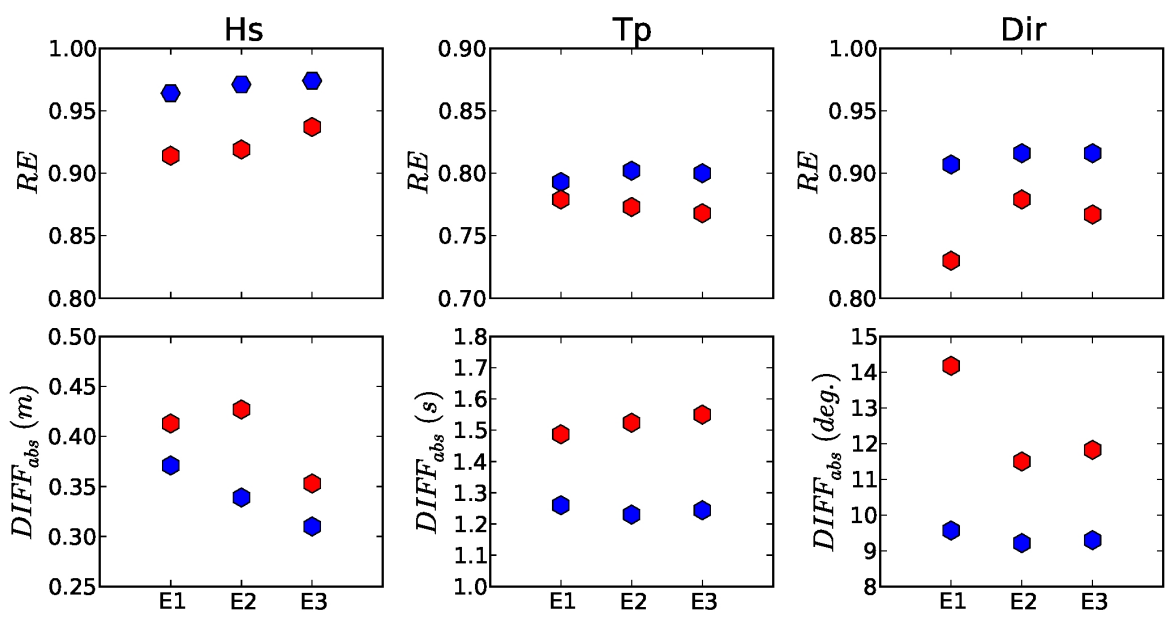

Figure 5: Index of agreement $R E$ and mean absolute difference $D I F F_{a b s}$ in predictions of significant wave height, peak period and mean wave directions, for the three configurations retained, in November 2012-March 2013, at points WB1 (•) and WB2 (O).
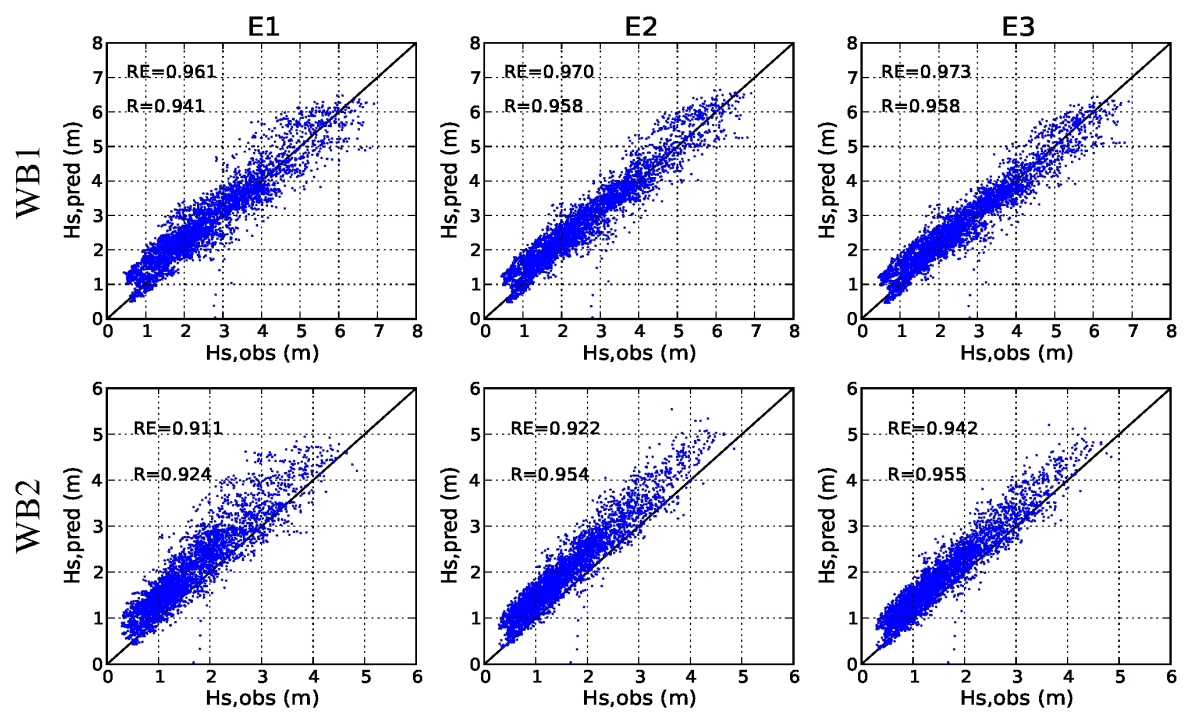

Figure 6: Scatter plots results for the evaluation of significant wave heights at wave buoys (top) WB1 and (bottom) WB2 in configurations E1-E3 when the tidal range exceeds $3 \mathrm{~m}$. 


\subsection{Improvements of numerical predictions}

The local comparisons of predictions between configurations E1 and E3 (Figs. 3-6) exhibit the importance of tide on the evolution of waves conditions in the Ushant-Molène archipelago. This influence is not only restricted to shallow waters (point WB2) but appears also in deep waters, as exhibited by semi-diurnal variations of $H_{s}$ with tide at wave buoy WB1. At this measurement point, tide-induced variations may thus account for nearly $30 \%$ of predicted $H_{s}$ without tide which is comparable to wave-heights evolutions in estuaries characterised by strong wave and tidal current interactions $[13,14]$. These numerical estimations are however consistent with predictions performed by Ardhuin et al. [21], by adding tidal forcings in the WaveWatch III model [47]. It compares also with the $20 \%$ modulation of $H_{s}$ exhibited by Hashemi et al. [22] in the Pentland Firth. In the present investigation, integrating tidal forcings in the wave simulation (configuration E2) improves thus predictions of $H_{s}$, at the offshore wave buoy, reducing the mean absolute difference by $9 \%$ (Fig. 5). Whereas reduced evolutions are noticed for wave period and direction, simulations with tide follow the same trend. Benefits of integrating tide in the wave modelling are also exhibited at the shallow-water wave buoy WB2 with noticeable improvements of predicted directions. The index of agreement $R E$ for the estimation of the wave direction increases thus from 0.83 to 0.88 between configurations $\mathrm{E} 1$ and E2. Nevertheless, predictions of $H_{s}$ appear to drop slightly with increase of $D I F F_{a b s}$ from $0.41 \mathrm{~m}$ in configuration E1 to $0.43 \mathrm{~m}$ in configuration E2 (Fig. 5). These differences are mainly associated to overestimations of the significant wave height with tide in comparison with predictions without tide. The inclusion of the dissipation term of wave energy, proposed by van der Westhuysen [27], is found to limit these overestimations of $H_{s}$, improving predictions of the significant wave height at the shallow-water wave buoy while restricting modifications of other parameters with respect to the default configuration E2 (Figs. 5 and 6). Differences obtained for the peak period appear finally negligible with respect to improvements reached in configuration E3.

\subsection{The tide-induced modulations of waves}

In order to explain further the tide-induced modulations of waves at both measurement sites, further investigation is conducted about tidal processes influencing waves conditions in the Ushant-Molène archipelago, focusing on current-induced refraction (Section 3.3.1) and waves breaking on negative current gradients (Section 3.3.2).

\subsubsection{Current-induced refraction}

The major influence of currents on waves in the Ushant-Molène archipelago is confirmed here with reduced differences between predictions neglecting and integrating tidal free-surface elevations, mainly restricted to tidal flats. As exhibited by Ardhuin et al. [21], the large-scale tide-induced variations of waves are mostly explained by refraction over currents. Whereas these effects have been primary exhibited for waves from 
the northwest, the present investigation focuses on waves from the west-northwest which account for the major part of incoming waves off Ushant-Molène archipelago [8]. Figs. 7 and 8 compare the evolutions of the significant wave height without (configuration E1) and with (configuration E3) tidal forcings during high (time T1) and low (time T2) tides of 12 January 2013. During high tide, northeastern tidal currents, which develop around the western part of Ushant island, induce veering of incoming waves towards the south in the southern part of the area of interest, increasing the exposition of western Ushant island and the Fromveur Strait (wave buoy WB2) and the southeastern region (wave buoy WB1) (Figs. 8 and 9). During low tide, southwestern currents, which develop in the Fromveur Strait and west of Ushant island, refract waves from the west towards the north-east direction in the southwestern entrance of Ushant-Molène archipelago, reducing $H_{s}$ in the southeastern part of the Fromveur Strait and around the deep-water wave buoy. As noticed by Ardhuin et al. [21], these effects are reinforced, between 1 and 2 hours after low tide, by the development of a westward current jet, in the south of Ushant island, responsible for trapping incoming waves while exhibiting a southeastern shadow area with reduced $H_{s}$. The local increase of the significant wave height in the tidal strait is mainly associated to accelerating opposing currents and will be more precisely discussed in the next section. At both measurement sites, predicted significant wave heights with tide (configuration E3) appear finally nearly in phase with the tidal free-surface elevation (Figs. 2 and

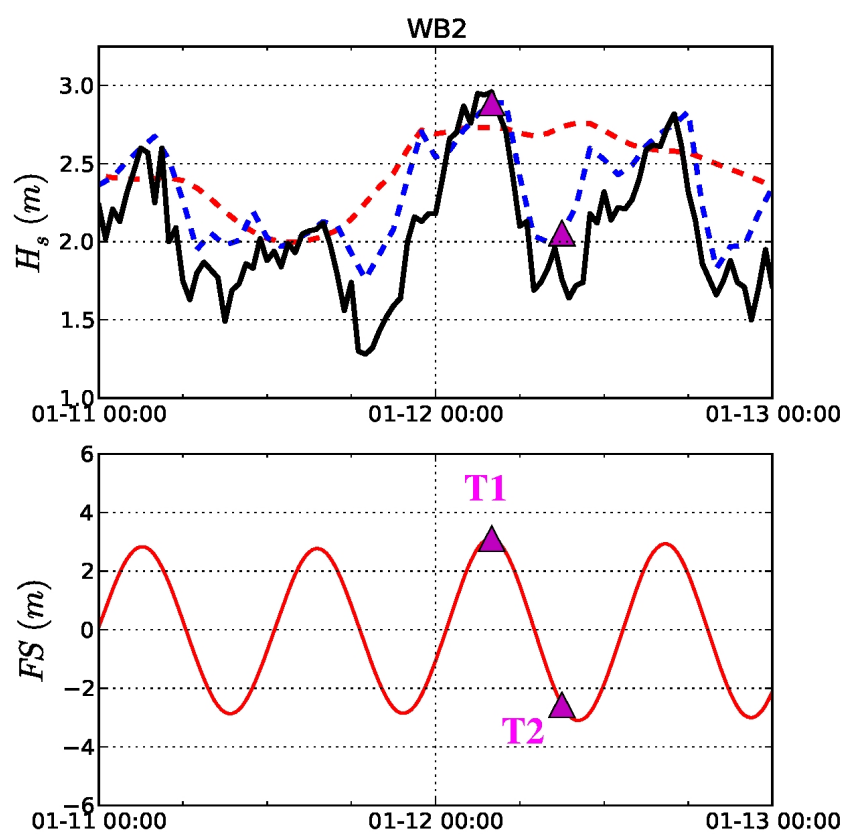

Figure 7: Time series of (top) significant wave height observed (black continuous line) and predicted without (configuration E1, red dotted line) and with (configuration E3, blue dotted line) tides at point WB2 and (bottom) tidal free-surface elevation in the Fromveur Strait from 11 to 13 January 2013. 

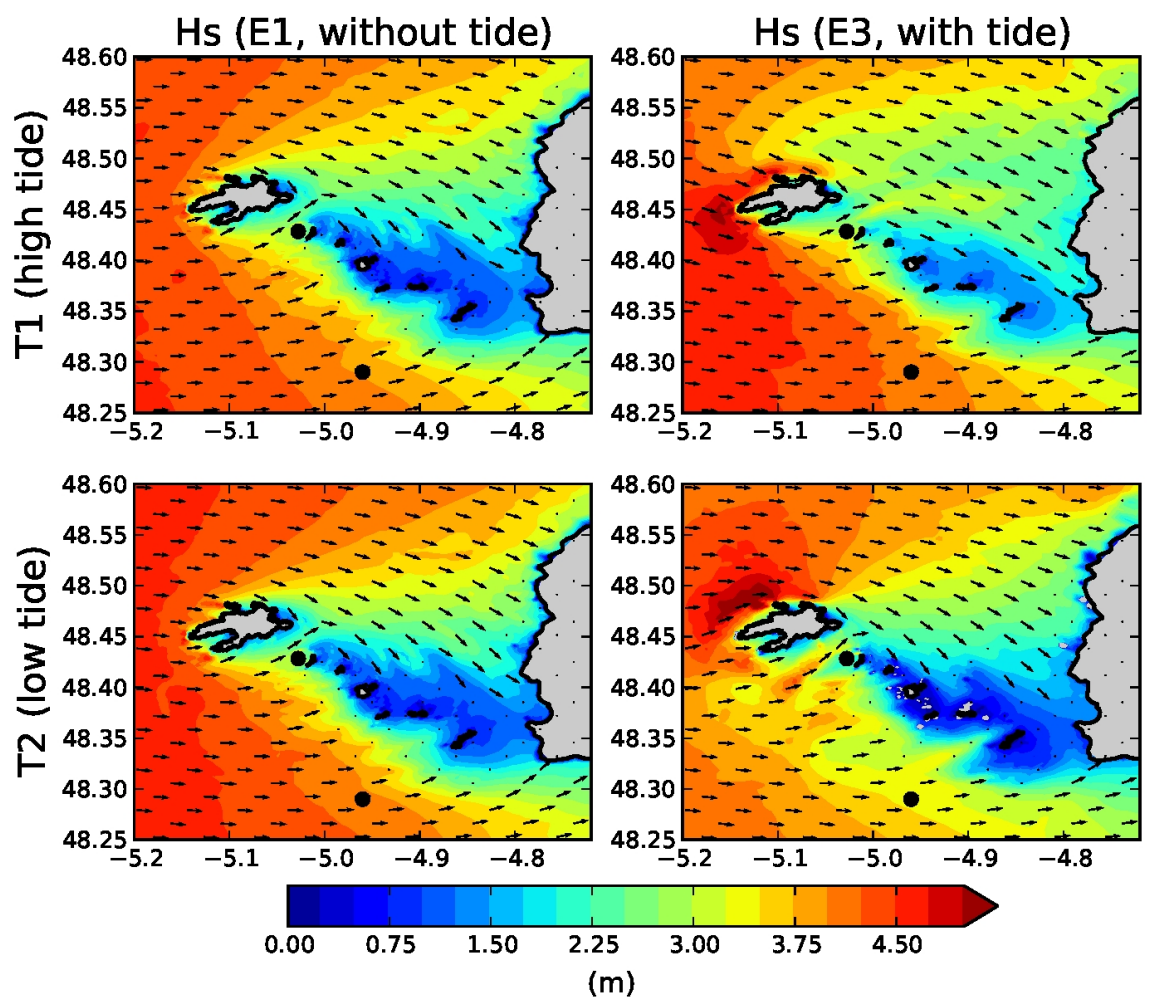

Figure 8: Significant wave heights without (right, configuration E1) and with (left, configuration E3) tides at high (time T1) and low (time T2) tides of 12 January 2013. Black circles show locations of wave buoys WB1 and WB2.

7). Higher $H_{s}$ are obtained during high tide whereas lower values appear during low tide. The mean wave direction tends furthermore to veer to the south-east at high tide and to the north-east at low tide, the amplitude of these modifications approaching $10-20^{\circ}$ (Figs. 3 and 4). Similar processes are identified in the northern part of Ushant-Molène archipelago. During high-tide, tidal currents around Ushant island are thus refracting waves towards the south-east increasing the significant wave height in the proximal northern area of Molène archipelago (Figs. 8 and 9). This results, at the same time, in lower $H_{s}$ further north. A reverse situation is, as a first approximation, obtained during low tide. These evolutions result in phase shift between significant wave heights and tidal forcings. While $H_{s}$ follows the evolution of tidal free-surface elevation close to Molène archipelago, opposite evolutions are obtained further north with highest wave amplitude during low tide.

\subsubsection{Waves breaking by opposing currents}

The complex influences of currents on waves are exhibited by the spatial distribution of mean relative differences in $H_{s}$ predictions between configurations integrating (E2) and neglecting (E1) tidal currents (Fig. 10-a). These synoptic differences confirm, in particular, the increase exposition of the northern 

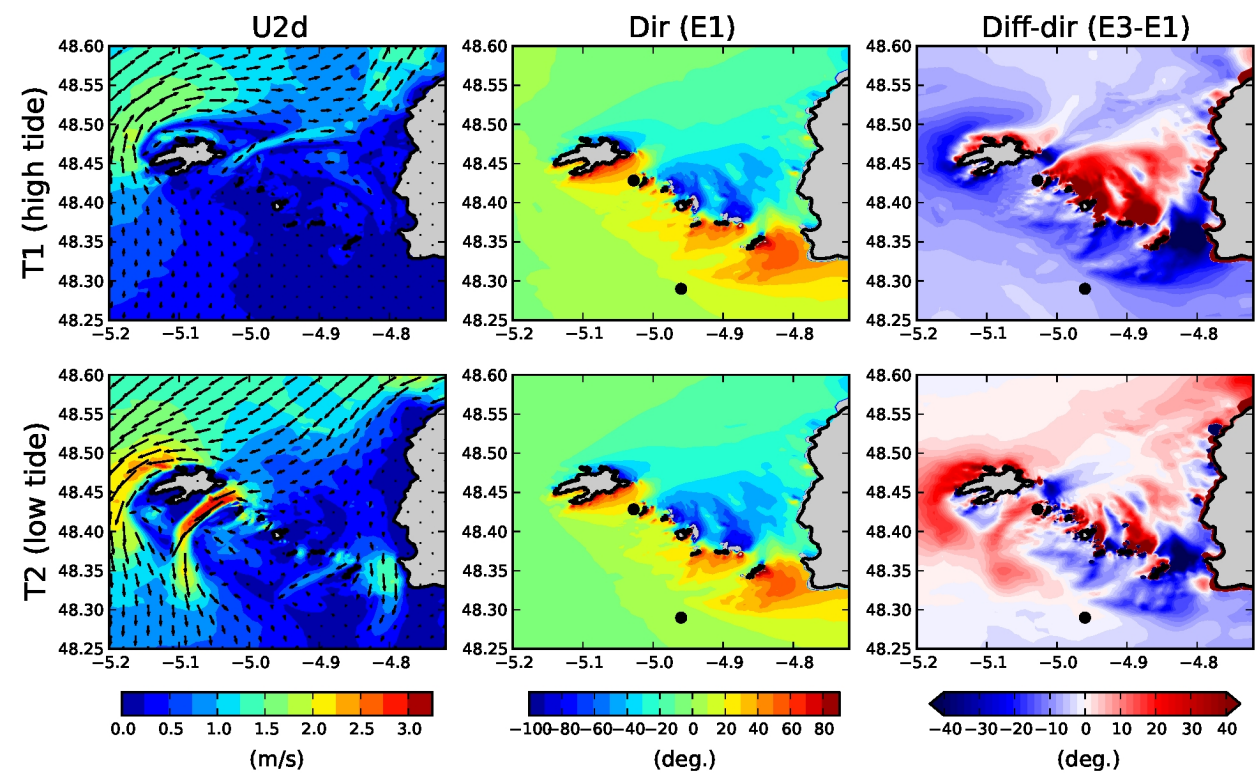

Figure 9: (left) Depth-averaged tidal currents, (middle) incoming wave direction in configuration E1 (anticlockwise convention from the East) and (right) differences in predicted wave directions between configurations E3 and E1 at high (time T1) and low (time T2) tides of 12 January 2013. Positive and negative values of predicted differences (right) show waves veering effects towards the north-east and the south-east, respectively.
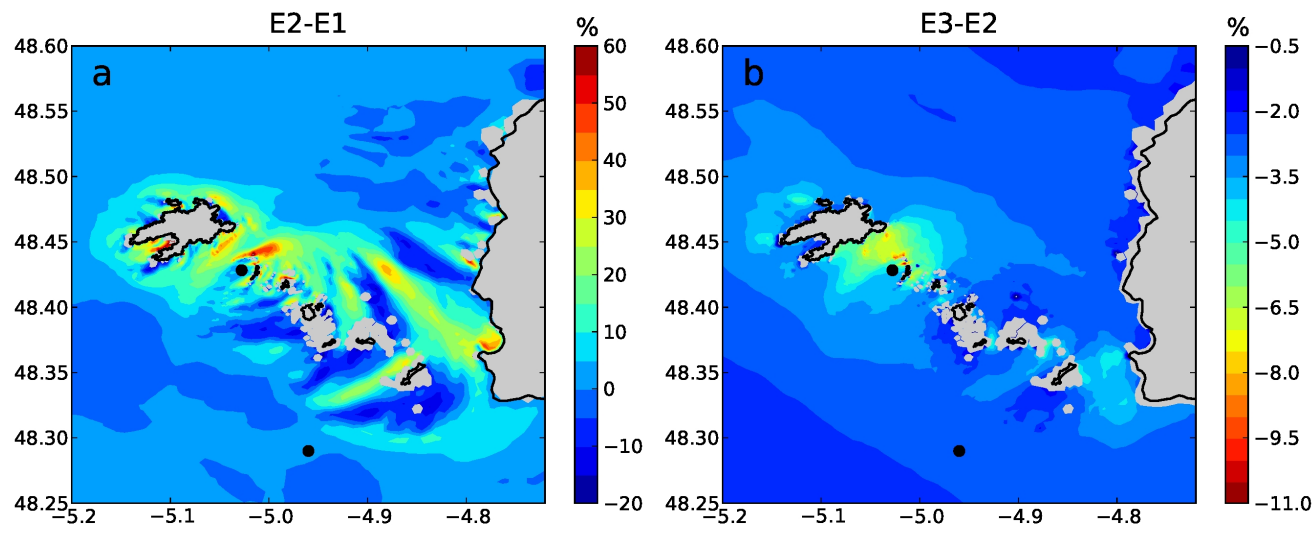

Figure 10: Mean relative differences (a) $100 D I F F_{r e l}(E 2-E 1) / H_{s, m e a n}(E 1)$ and (b) $100 D I F F_{r e l}(E 3-E 2) / H_{s, m e a n}(E 2)$ for the predictions of the significant wave height in Ushant-Molène archipelago with respect to the averaged $H_{s}$ over the period November 2012 - March 2013. Greys areas delimit tidal flats in nearshore regions and around islands.

part of Ushant-Molène archipelago, previously identified (Section 3.3.1). At both measurements sites, tideinduced modulations of $H_{s}$ account however for less than $10 \%$ of mean relative differences over the time period considered. More important differences, over $30 \%$ of averaged $H_{s}$, are thus identified in narrow straits between islands and shoals of Ushant-Molène archipelago with values over $40 \%$ in the north-eastern entrance of the Fromveur Strait. These significant variations are mainly attributed to increase of predicted 
$H_{s}$ by partially blocking opposing currents facing refracted incoming waves in the Fromveur Strait. The inclusion of the dissipation term of waves breaking on negative current gradients (Eq. 1) limits however this increase in the north-eastern part of the Fromveur Strait (Fig. 10-b). Over this area, the reduction of $H_{s}$ in configuration E3 accounts thus, in averaged, for more than $7 \%$ of the mean significant wave height predicted in the default configuration with tide (E2). This provides also further explanations about improvements of numerical predictions in configuration E3 (Section 3.2). Indeed, the tendency to overestimate $H_{s}$ is typical of predictions with third-generation spectral wave models in areas with strong current gradients [24, 27, 48]. The additional dissipation term improves thus predictions at the shallow-water wave buoy by restricting the increase of predicted $H_{s}$ in the Fromveur Strait. These effects are localised to areas with strong current gradients, namely narrow straits between islands and shoals of Ushant-Molène archipelago, which explains why reduced modifications of $H_{s}$ are obtained at the deep-water wave buoy.

\subsection{The effects of tidal currents on the wave power resource}

A preliminary study is conducted here to exhibit a noticeable effect of wave and current interactions in tidal stream sites. In the perspective of the implementation of wave energy converters (WEC) complemented tidal stream energy devices, further investigation is thus conducted about effects of tidal currents on the wave power resource in the area of interest. Whereas local differences may exist between the spatial distribution of $H_{s}$ and $P$ in relation to the influence of the group velocity on the computation of the wave energy flux [38], predictions established here show similar patterns (Fig. 11) confirming regional numerical investigations conducted by Guillou and Chapalain [20,49] and Guillou [30] at the scale of western Brittany. Both quantities present thus highest values in the exposed region west of Ushant island while experiencing strong energy dissipation downstream islands and shoals of the area of interest. In configuration E1, the offshore mean wave power estimated around $P=28 \mathrm{~kW} \mathrm{~m}^{-1}$ decreases to $P=12 \mathrm{~kW} \mathrm{~m}^{-1}$ in the Fromveur Strait (Fig. 11-c). Whereas the inclusion of tidal currents, in configuration E3, results in evolutions of $H_{s}$ restricted to $45 \%$, wave power shows more significant variations over $100 \%$ in northern entrances of tidal straits. These differences are associated with the theoretical formulations of $H_{s}$ and $P$ [25]. Indeed, while the significant wave height is computed from the square root of total wave energy $\left(H_{s}=4 \int_{0}^{2 \Pi} \int_{0}^{\infty} E d \sigma d \theta\right)$, the wave power is defined as the evolution of wave energy transport by the group velocity $c_{g}$ and the projected tidal current $u\left(P=\rho g \int_{0}^{2 \Pi} \int_{0}^{\infty}\left(c_{g}+u\right) E d \sigma d \theta\right.$ with $\rho$ the water density and $g$ the acceleration of gravity). In deep water, assuming linear Airy wave theory, the wave energy flux is thus directly proportional to $c_{g}+u$ and $H_{s}^{2}$ as $P=\rho g H_{s}^{2}\left(c_{g}+u\right) / 16[25,50]$. As current has more influence on $E$ than on $c_{g}+u$, this results in stronger increase of the wave power than the significant wave height, even in conditions of waves propagation on opposing currents [22]. Whereas this increase of wave power lies over the $30 \%$ variations reported by Barbariol et al. [17] in the Gulf of Venice, it is consistent with variations of the wave energy flux of $60 \%$ predicted by Saruwatari et al. [9] in the tidal stream energy site of the Pentland Firth (Orkney archipelago). 

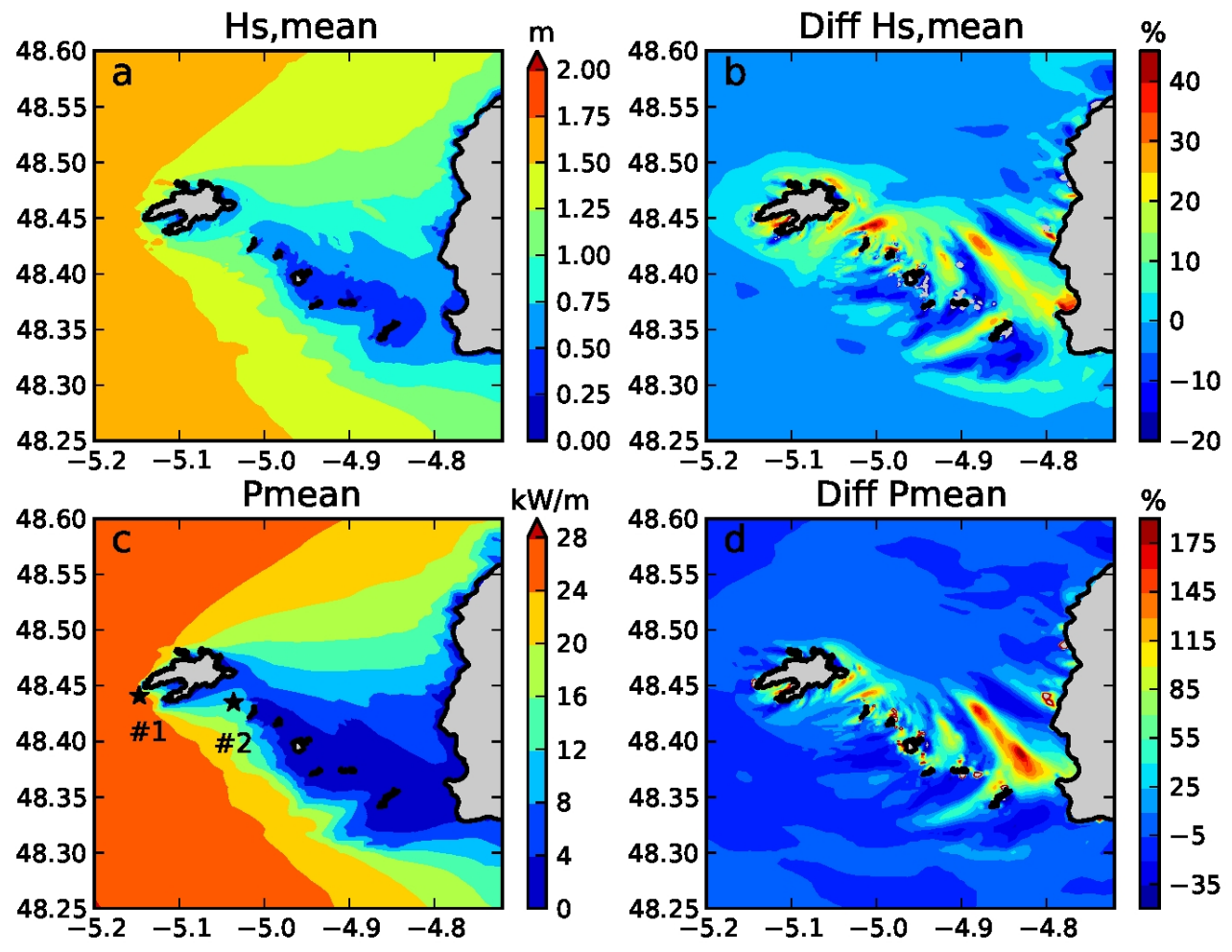

Figure 11: Averaged (a) significant wave height and (c) wave power in configuration E1 in November 2012 - March 2013. Relative differences, with respect to the reference configuration E1, in predictions of averaged (b) $H_{s}$ and (d) $P$ between configurations E3 and E1. Positive and negative values account for increase and reduction of predicted values in configuration E3, respectively.

In order to provide further information for potential WEC selection, design and optimisation in the area of interest, tide-induced modulations of wave power are investigated at two locations titled $\# 1\left(\lambda=5.147^{\circ} \mathrm{W}\right.$, $\left.\phi=48.441^{\circ} \mathrm{N}\right)$ and $\# 2\left(\lambda=5.036^{\circ} \mathrm{W}, \phi=48.435^{\circ} \mathrm{N}\right)$, off the exposed region of Ushant island and in the Fromveur Strait (Figs. 11 and 12). The wave energy flux shows, at both locations, strong monthly variability in accordance with the evolution of wave climate in winter 2012-2013 over the area of interest $[20,51]$. Off the isle of Ushant (point \#1), $P$ (in configuration E1) increases thus from $35.2 \mathrm{~kW} \mathrm{~m}^{-1}$ in November 2012 to $63.2 \mathrm{~kW} \mathrm{~m}^{-1}$ in December 2012. As exhibited in Fig. 11, tidal currents increase wave power at both locations. Whereas these variations account for nearly $10 \%$ of $P$ off Ushant (\#1), more significant relative evolutions are predicted in the Fromveur Strait (\#2) with increase of monthly wave power by $37 \%$ in February 2013. Despite its predictable characteristics, tide contributes thus to the interannual and seasonal variabilities of available wave power in the tidal stream energy site of the Fromveur Strait, with possible difficulties in the operation of wave energy devices designed for conditions neglecting the influence of tidal currents [22]. WEC selection is this environment has to integrate these effects. 


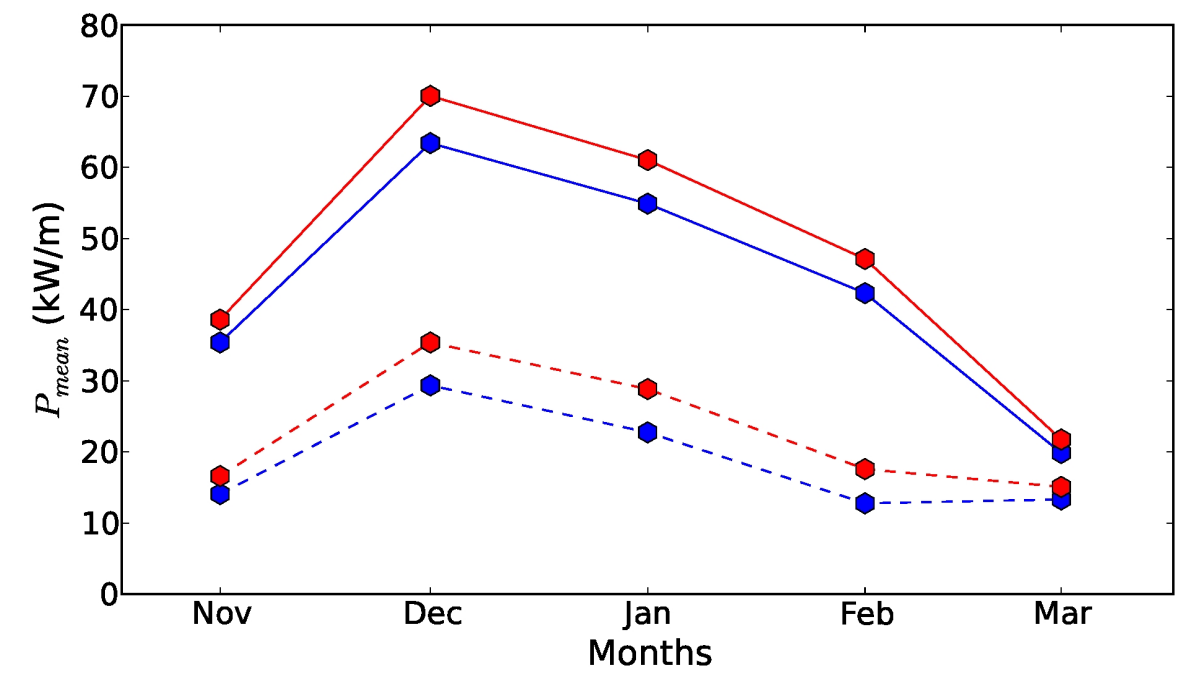

Figure 12: Monthly time series of wave power in configurations (blue) E1 and (red) E3 at points (continuous line) \#1 and (dotted line) \#2 in November 2012 - March 2013.

\section{Conclusions}

A modified version of the wave propagation model SWAN (version 41.01), coupled with the tidal depthaveraged circulation model TELEMAC 2D, has been set up in the regional extend of the tidal stream energy site of the Fromveur Strait to investigate and evaluate the effects of tidal currents on waves in this area. Particular attention is devoted to current-induced refraction and waves breaking on negative current gradients. Numerical results have been compared with a series of available in-situ measurements of the significant wave height, the peak period and the mean wave direction at two locations, off and within the tidal strait. The main outcomes of the present study are the following:

1. Current-induced refraction is found to lead to significant semi-diurnal modulations of $H_{s}$ at both measurement sites. Whereas this process arises in areas with strong current gradients west of Ushant island and in the Fromveur Strait, its effects appear also off this region with variations of the significant wave height of nearly $30 \%$ at the deep-water wave buoy. Benefits of integrating tidal forcings in the default version of the wave model are thus assessed at both measurement points.

2. A slight tendency to overestimate $H_{s}$ is however exhibited at the shallow-water wave buoy in conditions of waves opposed to currents in the Fromveur Strait. Whereas the additional dissipation term of waves breaking on negative current gradients is not suited to fully blocking conditions, where non linear effects have to be considered, its inclusion in the wave model improves predictions of $H_{s}$ at this measurement point, limiting the increase of the significant wave height in the north-eastern part of the Strait.

3. The inclusion of tidal currents results in strong increases of wave power, over $100 \%$, in northern entrances of tidal straits. A detailed investigation at two potential locations for WEC implementation 
shows variations of $10 \%$ in the exposed region west of Ushant island and $37 \%$ at the center of the Fromveur Strait. Potential WEC developers have thus to integrate these variations to optimise efficiency of wave energy converters.

Whereas extended concurrent measurements, including wave-buoys records or data from high-frequency radars, will be required to assess models performances in the study site, these results suggest the inclusion of tidal forcings in wave simulations applied to areas with strong wave and current interactions. In the present investigation, this appears as a prerequesite for a refined quantification of the extractable technical wave power from energy converters. In this perspective, particular attention has to be devoted to the parameterisation of wave energy dissipation, fundamental in avoiding unrealistic increase of $H_{s}$. These refined numerical estimations of waves will help to quantify the induced modulations of available tidal stream power and loads on associated energy converters. This is especially the case for the previous estimation of waves effects on the tidal energy resource of the Fromveur Strait which under-estimated current-induced modulations of waves. In the context of the environmental impact of tidal stream farms, these improved waves predictions will finally upgrade numerical simulations of changes induced on sediment transport rates and bed supplies.

\section{Acknowledgements}

Wave buoy data was provided by the French CANDHIS database ("Centre d'Archivage National de Données de Houle In Situ", Cerema, http://candhis. cetmef.developpement-durable.gouv.fr/). Wave forcings at open boundaries of the wave model were obtained from regional runs of WaveWatch III within the context of the IOWAGA project (http://wwz. ifremer.fr/iowaga/Products). Simulations were performed on computer facilities CAPARMOR ("CAlcul PARallèle Mutualisé pour l'Océanographie et la Re-

cherche"). The present paper is a contribution to the research program of the Laboratory of Coastal Engineering and Environment (Cerema, http://www.cerema.fr, http://memphys-lgce.fr.ht).

\section{References}

[1] R. Carballo, G. Iglesias, A. Castro, Numerical model evaluation of tidal stream energy resources in the Ría de Muros (NW Spain), Renewable Energy 34 (2009) 1517-1524.

[2] P. Work, K. Haas, Z. Defne, T. Gay, Tidal stream energy site assessment via three-dimensional model and measurements, Applied Energy 102 (2003) 510-519.

[3] A. Pacheco, Ó. Ferreira, R. Carballo, G. Iglesias, Evaluation of the production of tidal stream energy in an inlet channel by coupling field data and numerical modelling, Energy 71 (2014) 104-117.

[4] M. Lewis, S. Neill, P. Robins, M. Hashemi, Resource assessment for future generations of tidal-stream energy arrays, Energy 83 (2015) 403-415. 
[5] T. Jesus Henriques, S. Tedds, A. Botsari, G. Najafian, T. Hedges, C. Sutcliffe, I. Owen, R. Poole, The effects of wavecurrent interaction on the performance of a model horizontal axis tidal turbine, International Journal of Marine Energy 8 (2014) 17-35.

[6] S. Tatum, C. Frost, M. Allmark, D. O'Doherty, A. Mason-Jones, P. Prickett, R. Grosvenor, C. Byrne, T. O'Doherty, Wave-current interaction effects on tidal stream turbine performance and loading characteristics, International Journal of Marine Energy 14 (2016) 161-179.

[7] M. Hashemi, S. Neill, P. Robins, A. Davies, M. Lewis, Effect of waves on the tidal energy resource at a planned tidal stream array, Renewable Energy 75 (2015) 626-639.

[8] N. Guillou, G. Chapalain, S. P. Neill, The influence of waves on the tidal kinetic energy resource at a tidal stream energy site, Applied Energy 180 (2016) 402-415.

[9] A. Saruwatari, D. Ingram, L. Cradden, Wave-current interaction effects on marine energy converters, Ocean Engineering 73 (2013) 106-118.

[10] S. Neill, M. Hashemi, M. Lewis, The role of tidal asymmetry in characterizing the tidal energy resource of Orkney, Renewable Energy 68 (2014) 337-350.

[11] N. Guillou, J. Thiébot, The impact of seabed rock roughness on tidal stream power extraction, Energy 112 (2016) $762-773$.

[12] E. Rusu, M. Bernardino, C. G. Soares, Modelling the influence of currents on wave propagation at the entrance of the Tagus estuary, Ocean Engineering 38 (2011) 1174-1183.

[13] N. Guillou, G. Chapalain, Modeling the tide-induced modulation of wave height in the outer Seine estuary, Journal of Coastal Research 28 (2012) 613-623.

[14] G. Dodet, X. Bertin, N. Bruneau, A. B. Fortunato, A. Nahon, A. Roland, Wave-current interactions in a wave-dominated tidal inlet, Journal of Geophysical Research 118 (2013) 1587-1605.

[15] I. Fairley, R. Ahmadian, R. Falconer, M. Willis, I. Masters, The effects of a Severn Barrage on wave conditions in the Bristol Channel, Renewable Energy 68 (2014) 428-442.

[16] A. S. Iyer, S. J. Couch, G. P. Harrison, A. R. Wallace, Variability and phasing of tidal current energy around the United Kingdom, Renewable Energy 51 (2013) 343-357.

[17] F. Barbariol, A. Benetazzo, S. Carniel, M. Sclavo, Improving the assessment of wave energy resources by means of coupled wave-ocean numerical modeling, Renewable Energy 60 (2013) 462-471.

[18] E. Boudière, C. Maisondieu, F. Ardhuin, M. Accensi, L. Pineau-Guillou, J. Lepesqueur, A suitable metocean hindcast database for the design of marine energy converters, International Journal of Marine Energy 3-4 (2013) 40-52.

[19] M. Hashemi, S. Neill, The role of tides in shelf-scale simulations of the wave energy resource, Renewable Energy 69 (2014) $300-310$.

[20] N. Guillou, G. Chapalain, Numerical modelling of nearshore wave energy resource in the Sea of Iroise, Renewable Energy 83 (2015) 942-953.

[21] F. Ardhuin, A. Roland, F. Dumas, A.-C. Bennis, A. Sentchev, P. Forget, J. Wolf, F. Girard, P. Osuna, M. Benoit, Numerical wave modeling in conditions with strong currents: dissipation, refraction, and relative wind, Journal of Physical Oceanography 42 (2012) 2101-2120.

[22] M. Hashemi, S. Grilli, S. Neill, A simplified method to estimate tidal current effects on the ocean wave power resource, Renewable Energy 96 (2016) 257-269.

[23] O. M. Phillips, On the response of short ocean wave components at a fixed wavenumber to ocean current variations, Journal of Physical Oceanography 14 (1984) 1425-1433.

[24] A. Chawla, J. T. Kirby, Monochromatic and random wave breaking at blocking point, Journal of Geophysical Research 107 (Issue C7) (2002) 4-1-4-19.

[25] L. Holthuijsen, Waves in Oceanic and Coastal Waters, Cambridge University Press, Cambridge, 2007. 
[26] L. Holthuijsen, H. Tolman, Effects of the Gulf Stream on ocean waves, Journal of Geophysical Research 96 (1991) 1275512771 .

[27] A. van der Westhuysen, Spectral modeling of wave dissipation on negative current gradients, Coastal Engineering 68 (2012) 17-30

[28] SHOM, Courants de marée - Côte Ouest de Bretagne, Technical Report, Service Hydrographique et Océanographique de la Marine (1994).

[29] A. Sentchev, P. Forget, Y. Barbin, M. Yaremchuk, Surface circulation in the Iroise Sea (W. Brittany) from high resolution HF radar mapping, Journal of Marine Systems 109-110 (2013) S153-S168.

[30] N. Guillou, Evaluation of wave energy potential in the Sea of Iroise with two spectral models, Ocean Engineering 106 (2015) 141-151.

[31] R. Moreira, D. Peregrine, Non-linear interactions between deep-water waves and currents, Journal of Fluid Mechanics 691 (2012) 1-25.

[32] N. Booij, R. Ris, L. Holthuijsen, A third-generation wave model for coastal regions, 1. Model description and validation, Journal of Geophysical Research 104 (C4) (1999) 7649-7666.

[33] S. team, SWAN Cycle III. Version 41.01 AB - Scientific and technical documentation, Technical report, Delft University of Technology (2015).

[34] G. Komen, L. Cavaleri, M. Donelan, K. Hasselmann, S. Hasselmann, P. Janssen, Dynamics and modelling of ocean waves, Cambridge University Press, Cambridge, 1994

[35] A. van der Westhuysen, M. Zijlema, J. Battjes, Nonlinear saturation based whitecapping dissipation in SWAN for deep and shallow water, Coastal Engineering 54 (2007) 151-170.

[36] R. Lai, S. Long, N. Huang, Laboratory studies of wave-current interaction - kinematics of the strong interaction, Journal of Geophysical Research Oceans 94 (1989) 16201-16214.

[37] I. Suastika, M. de Jong, J. Battjes, Experimental study of wave blocking, in: Coastal Engineering, Sydney, Australia, 2000, pp. 227-240.

[38] E. Rusu, C. G. Soares, Numerical modelling to estimate the spatial distribution of the wave energy in the Portuguese nearshore, Renewable Energy 34 (2009) 1501-1516.

[39] M. Gonçalves, P. Martinho, C. Soares, Wave energy conditions in the western French coast, Renewable Energy 62 (2014) $155-163$.

[40] J. M. Hervouet, Hydrodynamics of free surface flows, modelling with the finite element method, Cambridge University Press, Cambridge, 2007.

[41] N. Guillou, Wave energy dissipation by bottom friction in the English Channel, Ocean Engineering 82 (2014) $42-51$.

[42] A. Roland, F. Ardhuin, On the developments of spectral wave models: numerics and parameterizations for the coastal ocean, Ocean Dynamics - Topical Collection of the 7th International Conference on Coastal Synamics 64 (6) (2014) $833-846$

[43] Saha et al., The NCEP Climate Forecast System Version 2, Journal of Climate 27 (2014) 2185-2208.

[44] F. Ardhuin, IOWAGA project, https://wwz.ifremer.fr/iowaga/ (2016).

[45] C. J. Willmott, On the validation of models, Physical Geography 2 (2) (1981) 219-232.

[46] SHOM, http://datashom.fr (2016).

[47] H. Tolman, User manual and system documentation of WAVEWATCH-III version 3.14, Tech. rep., NOAA/NWS/NCEP/MMAB (2009).

[48] R. C. Ris, L. H. Holthuijsen, Spectral Modelling of Current Wave-blocking, in: Proc. 25th Int. Conf. on Coastal Engineering, 1996, pp. 1247-1254.

[49] N. Guillou, G. Chapalain, Wave energy potential in the Sea of Iroise, in: 11th European Wave and Tidal Energy Conference 
Series, Nantes, France, 2015.

[50] R. Dalrymple, R. Dean, Water Wave Mechanics for Engineers and Scientists, Prentice-Hall, 1991.

[51] S. Neill, M. Hashemi, Wave power variability over the northwest European shelf seas, Applied Energy 106 (2013) 31-46. 